
do consumo de alimentos: das práticas de consumo para sobrevivência nas sociedades pré-capitalista ao consumo de alimentos como direito humano na contemporaneidade. Oikos: Família e Sociedade em Debate, v. 29, n. 1, p. 162-179, 2018.

DOI: http://dx.doi.org/10.31423/2236-8493.v29i1.364

\title{
Contexto socio-histórico do consumo de alimentos: das práticas de consumo para sobrevivência nas sociedades pré-capitalista ao consumo de alimentos como direito humano na contemporaneidade
}

\author{
Social historical context of food consumption: from consumer practices to survival in \\ pre-capitalist societies, to food consumption as a human right in the contemporary world
}

Mônica Gomes da Silva ${ }^{1}$ Joseana Maria Saraiva ${ }^{2}$

\section{Resumo}

As práticas de consumo de alimentos na história da sociedade desempenham papel importante desde épocas remotas. Do consumo de alimentos para sobrevivência nas sociedades pré-históricas ao consumo de alimentos como direito humano na sociedade contemporânea, um longo processo foi percorrido. Este estudo tem por objetivo refletir questões centrais acerca deste processo, na perspectiva de compreender os avanços e os retrocessos que o conformam na sociedade de consumo contemporânea, considerando o contexto das relações econômicas, políticas, sociais e culturais. Trata-se de pesquisa teórica, para a qual utilizou-se de revisão bibliográfica, valendo-se das contribuições dos diversos autores que tratam do assunto. Os resultados mostram a trajetória política, econômica, social e cultural das práticas de consumo alimentar, a partir da pré-história, e o desenvolvimento das ações de Segurança Alimentar e Nutricional, destacando as inter-relações do processo e suas contradições na efetivação do direito humano à alimentação adequada.

Palavras-chave: Práticas de consumo; Segurança alimentar e nutricional; Políticas públicas.

\begin{abstract}
The practices of food consumption in the history of society have played an important role since very remote times. From food consumption to survival, in prehistoric societies, to the consumption of food as a human right, in contemporary society, a long process has been traversed. The purpose of this study is to reflect the central questions about this process, with a view to understanding the advances and setbacks that shape it in contemporary consumer society, considering economic, political, social and cultural relations. It is a theoretical research, with a qualitative approach, for which a bibliographic review was used, using the contributions of the various authors who deal with the subject. The results show the political, economic, social and cultural trajectory of food consumption practices from prehistory and the development of Food and Nutrition Security actions worldwide, highlighting the interrelations of the process and its contradictions in the Human right to adequate food.
\end{abstract}

Keywords: Consumption practices; Food and nutritional security; Public policies

\footnotetext{
${ }^{1}$ Mestra em Consumo, Cotidiano e Desenvolvimento Social pela Universidade Federal Rural de Pernambuco. Nutricionista do Instituto Federal de Pernambuco.

2 Doutora em Serviço Social pela Universidade Federal de Pernambuco. Professora do Programa de Pós-Graduação em Consumo, Cotidiano e Desenvolvimento Social da Universidade Federal Rural de Pernambuco.
} 


\section{INTRODUÇÃO}

Este artigo tem por objetivo refletir questões centrais acerca das práticas de consumo de alimentos na história da sociedade, desde épocas muito remotas. A produção bibliográfica, que trata da existência do consumo, como prática cotidiana, considera que há profundas divergências e controvérsias acerca deste fenômeno social. A atualidade da questão e sua significação induzem à investigação, de forma ampla, deste fenômeno, a partir de formulações clássicas, recuperando o pensamento de Veblen (1982/ 1988), Marx (1983), Lojkine (1997), Campbell (2001), entre outros teóricos que vêm estudando como este fenômeno vem se comportando, historicamente, na sociedade, nas organizações e nos grupos, como resultado de variáveis econômicas, políticas, sociais e culturais.

Considerando as múltiplas relações desse contexto, antes do consumo ser concebido como objeto de estudo, o ser humano já promovia alterações diversas no ambiente em que vivia, de forma muito primitiva e limitada, para satisfazer suas necessidades básicas de consumo, sobretudo, de alimentos e garantir a sua sobrevivência. Assim, pode-se afirmar que o consumo, como prática cotidiana, sobretudo de alimentos, é essencial para garantir a sobrevivência dos seres humanos.

Nesse processo, destaca-se a importância crucial da segurança alimentar e nutricional, não somente relacionada com as contradições que podem levar a agudas crises de alimentos e até a fome, mas, também refletir sobre a disputa árdua entre interesses econômicos e políticos, muito conflitantes no contexto da sociedade de consumo contemporânea. Os estudos de Castro, 1984; L'abbate, 1988; Maluf, Menezes e Valente, 1996 / 2003; Belik, 2012; Leão, 2012; Tavares e Leal, 2012; Magalhães, 2014, entre outros, abordam a Segurança Alimentar e Nutricional no contexto mundial, nacional, valorizando a garantia do acesso à alimentação adequada como direito humano e social, destacando as conquistas e os avanços no campo dos conceitos e da legislação. Ao mesmo tempo, estes teóricos mostram a existência de problemas políticos, econômicos e sociais, que limitam os avanços e a efetivação do direito humano à Segurança Alimentar e Nutricional, na sociedade de consumo contemporânea.

\section{AS PRÁTICAS DE CONSUMO NAS SOCIEDADES: DA PRÉ-HISTÓRIA À IDADE ANTIGA}

As sociedades primitivas ou pré-históricas, não tinham Estado, nem escrita e nem tecnologia. No plano econômico, eram sociedades de economia de subsistência, sem produção de excedentes e, portanto, sem mercado e assim, segundo o critério da falta, são caracterizadas como sociedades desorganizadas política, econômico e socialmente. 
Segundo Veblen (1988 p. 5-13), o ato de consumir vai evoluir historicamente, simultâneo à trajetória da sociedade humana, que passou por quatro estágios culturais: selvageria pacífica, bárbara, predatória e pecuniária. Nos primeiros estágios, caracterizados como os mais primitivos, o consumo tinha origem da caça, da pesca e das guerras entre as tribos para a sobrevivência e o sustento de seus grupos. Para Veblen (1988, p. 19), originariamente, a humanidade buscava o consumo baseado em formas de subsistência mais justas com a natureza e as demandas do próprio homem. Nas fases seguintes, predatória e pecuniária, o processo de acumulação de riqueza, dos bens e de produtos passou a ser fator de diferenciação social e emulação, modificando o comportamento dos indivíduos na sociedade. Lívia Barbosa (2004, p. 7) corroborando o pensamento de Marx (1981; 1983) e de Veblen (1988), afirma que o consumo, seja para fins de satisfação de necessidades básicas e, ou, supérfluas, é uma atividade presente na sociedade humana e não somente a partir da sociedade contemporânea, como tem sido defendido por alguns intelectuais, acadêmicos, jornalistas e profissionais de marketing de diferentes áreas do conhecimento acadêmico.

Diamond (1987, p. 65) explica esta evolução a partir de épocas muito remotas. Achados arqueológicos evidenciam que, até a era das sociedades medievais, poucas pessoas sobreviviam naquela época, por causa do clima frio e seco e as dificuldades em encontrar alimentos, o que justifica expectativa de vida muito baixa, em torno dos 26 anos. Após este período, o clima aquece em virtude do fenômeno conhecido como aquecimento global. Surge a agricultura como modo de vida alternativo e menos instável que o modo de vida dos caçadores e coletores, não havendo mais a dependência exclusiva das variações da natureza ou da disponibilidade da caça.

Com o desenvolvimento da agricultura, e sem a necessidade de se deslocar de um local para outro, como acontecia na vida nômade, ocorre a fixação dos grupos humanos em territórios específicos. A população cresce em números absolutos, e, por conseguinte, aumenta a esperança de vida. A ação dos seres humanos sobre a natureza tornou-se mais intensa, passando os mesmos a subsistir da agricultura e da domesticação de animais. $O$ aperfeiçoamento das armas e dos utensílios propiciou a criação de novas estratégias de sobrevivência e de consumo para suprir necessidades de alimentação, habitação e vestuário, entre outras (MOTA, 1997, p. 6; SHAN, 2015, p.1).

Em algumas regiões, a abundância de cereais, especialmente aveia, trigo e cevada, propiciou o processo de desenvolvimento agrícola pelos povos antigos (RECINE E RADAELE, 2008, s/p.). A garantia do alimento possibilitou maior margem de segurança e permitiu que o homem se dedicasse a outras atividades que não fossem estritamente ligadas à mera 
sobrevivência. Nova organização social foi estabelecida com a formação de tribos unidas por laços familiares, a formação de aldeias e, mais tarde, a formação das primeiras cidades, situadas em áreas férteis às margens de grandes rios (PEDRO, 1995, p.12; NAVARRO, 2015, s/n).

O acesso à água dos rios, por meio de canais de irrigação, represas e a drenagem de áreas inundadas, e o aperfeiçoamento das ferramentas e das técnicas de agricultura contribuíram para a melhoria na produtividade agrícola, gerando, principalmente, excedentes de alimentos e promovendo o desenvolvimento do comércio e a organização das cidades com 0 aumento cada vez maior da população (MOTA, 1997, p. 13).

Neste contexto, segundo Shan (2015, p. 2), grupos mais adiantados tecnicamente passaram a exercer domínio sobre outros, dando origem a sociedades cada vez mais complexas e diversificadas. A descoberta do uso do metal transformou o homem em artesão, além de coletor, agricultor e pastor. Essa nova atividade ocasionou nova divisão de trabalho entre os membros da aldeia; a organização social tornou-se mais complexa, fazendo surgir as grandes civilizações da antiguidade.

\section{AS PRÁTICAS DE CONSUMO NAS SOCIEDADES: DA IDADE ANTIGA À IDADE MÉDIA}

$\mathrm{Na}$ Idade Antiga, diferentemente da época anterior, as sociedades não viviam em condições de penúria ou consumindo apenas para subsistência. Evidencia-se tendência da humanidade direcionada a consumo cada vez maior, não apenas de alimentos, mas de todos os itens possíveis a que se tinha acesso. O domínio das técnicas de manufatura possibilitou a produção artesanal de bens, como joalheria, tecelagem, vidraçaria e marcenaria, mas a maioria desses bens estava acessível apenas aos nobres por seu caráter luxuoso. A comercialização dessa produção acontecia pelas estradas que ligavam as cidades, e com o desenvolvimento das navegações, esses produtos passaram a ser exportados (PEDRO, 1995, p. 45).

Entre os filósofos gregos, a busca de riqueza era considerada um mal e a ambição um vício, pensamento que dificultou o desenvolvimento da economia. Embora os gregos não considerassem o comércio atividade natural, as trocas não eram condenáveis, pois permitiam a diversificação das necessidades humanas, levavam à especialização dos produtores e facilitavam as trocas da moeda (SOUZA, 2015, p. 2). Estas práticas facilitaram a formação de uma classe de comerciantes ricos, que priorizavam a busca da riqueza em prejuízo das práticas das virtudes e do bem comum. Segundo Souza (2015, p. 2), os gregos condenavam estas práticas, temendo exatamente isto, a acumulação de moeda, a existência do trabalho remunerado e a cobrança de juros nos empréstimos. 
As cidades antigas eram, na verdade, muito mais centros de consumo do que de produção e, em função disso, a circulação de bens (produtos para obtenção de ganhos) desempenhou papel importante no maior desenvolvimento do comércio. A manufatura e exportação desenvolvidas entre as cidades, a importação de cereais e a compra de escravos favoreceram interesses comerciais específicos a cada cidade e o desenvolvimento da política (DEININGER 2012, p. 70).

Para Weber, segundo Deininger (2012, p. 70), a Antiguidade teria conhecido economia capitalista em certa medida relevante. Isto porque a economia baseada em produção doméstica fechada, ampliada pelo trabalho escravo, tendia a desaparecer em várias partes do mundo ocidental e o trabalho livre ganhava maior significado, contribuindo para a estruturação preliminar do capitalismo, embora de forma ainda embrionária. Já entre os romanos, segundo Souza (2015, p.3), o espírito imperialista levou à expansão das trocas de produtos entre Roma e as nações conquistadas. A riqueza era sempre bem-vinda e se obtinha pela dominação de outros povos conquistados e obrigados a produzir os bens que os romanos necessitavam consumir, bem como pela construção de estradas e aquedutos, com o fim de facilitar o transporte e a troca de bens (produtos alimentares de origem animal e vegetal) entre as cidades.

$\mathrm{Na}$ cultura romana, a agricultura era a principal fonte de riqueza e os produtos agrícolas eram comercializados ao redor do Mediterrâneo e transportados por via marítima para as cidades mais distantes que não produziam alimentos suficientes (PITTA, 2010, s/n).

Batista (2012, p. 3) e Shan (2015, p.2) salientam que, com a decadência do Império Romano e as invasões bárbaras, iniciou-se a Idade Média, marcada pela criação de comunidades agropastoris, sendo muitas dessas comunidades subordinadas a um reino, desenvolvendo-se, assim, o feudalismo, estrutura econômica, política, social e cultural caracterizada por grandes propriedades agrárias independentes e autossuficientes, cercadas por muros, onde a população vivia sob o poder do senhor feudal.

\section{AS PRÁTICAS DE CONSUMO NAS SOCIEDADES: DA IDADE MÉDIA À IDADE MODERNA}

A Idade Média caracteriza-se pela economia ruralizada, enfraquecimento comercial, supremacia da Igreja Católica e sistema de produção feudal. A sociedade era hierarquizada, composta por várias classes sociais: a nobreza feudal, o clero, os servos e os pequenos artesãos. A nobreza se constituía dos senhores feudais, cavaleiros, condes, duques e viscondes, detentores de terras e arrecadadores de impostos dos camponeses. O clero (membros da lgreja Católica) tinha grande poder, pois era responsável pela proteção espiritual da sociedade, era 
isento de impostos e ainda arrecadava o dízimo. Os servos (camponeses) e os pequenos artesãos compunham a terceira camada. Na base do sistema feudal estavam os servos, que viviam em cidades com muros altos para proteção contra inimigos. Estas cidades passaram a ser locais de trocas de produtos e especiarias, transformando-se em verdadeiros mercados que favoreciam o desenvolvimento do comércio, as corporações de ofício e a especialização do trabalho (BATISTA, 2012, p. 3; SHAN, 2015, p. 2).

Embora se constate por um lado que o desenvolvimento das cidades foi marcado por períodos de guerras e por populações devastadas por epidemias e fome, também se verifica por outro lado que a cidade de Constantinopla tinha aproximadamente um milhão de habitantes que consumiam grande variedade de produtos, que atendiam outras necessidades além daquelas de subsistência, características da Pré-História e da Idade Antiga. Ampla variedade de produtos e especiarias era comercializada, encontravam-se pérolas, perfumes, tapetes de luxo, peles, assim como tecidos de seda oriundos da Síria. Compravam-se, também, alimentos como trigo, peixe, mel e bebidas, como os vinhos, estes últimos provenientes da Europa (SOUZA, 2015, p. 4). O sofrimento da população não impedia a classe alta, sobretudo a nobreza feudal, de consumir produtos diferenciados daqueles que consumiam os servos e os artesãos, no que concerne a alimentos, bebidas, vestuário, acessórios e bens para ambientação.

Para Lima (2007, p. 25), o consumo nessa sociedade, enquanto compra de bens (produtos) e de serviços, era reservado, exclusivamente, para a nobreza, e estava associado ao status. Os reis e os senhores feudais podiam consumir muito e da melhor qualidade, enquanto os servos teriam que se contentar em produzir para os dois primeiros.

O peixe era alimento muito consumido, por ser barato e popular, e a pesca do arenque foi responsável pela prosperidade de várias cidades. Muitos mosteiros e castelos nobres mantinham viveiros para criação de peixes, como a truta e o salmão. Nesse período, o consumo alimentar era mais valorizado que o luxo de outros produtos, como vestuário e outros bens de consumo. O gosto pelas especiarias era grande, a noz-moscada e a pimenta-do- reino, bem como o açúcar, e, sobretudo, os cereais, principalmente o trigo, eram considerados produtos de primeira necessidade e estavam limitados à mesa dos reis e dos senhores ricos, por serem raros e caros (FAUSTO, 1996, p.14).

Neste período, a base da alimentação era essencialmente carnívora. Grandes quantidades de gado eram abatidas no início do verão, quando as forragens acabavam no campo. A carne era armazenada e, precariamente, conservada pelo sal, pela defumação ou simplesmente pelo sol. Esses processos, usados também para conservar o peixe, deixavam os 
alimentos intragáveis, e, desse modo, os condimentos/especiarias eram utilizados para disfarçar o sabor e o odor desagradável (Op. cit, 1996, p.14.).

Segundo Santos (2007, s/p), a questão alimentar tinha função estruturante na organização econômica e social na Idade Média por causa das crises periódicas na produção de alimentos, vinculadas às penúrias causadas, sobretudo, pela falta de cereais, principalmente do trigo. Franco Junior (2001, s/p) salienta que pelo menos cinco períodos de fome generalizada e de grande escassez de alimentos foram verificados em todo ocidente. Em função disso, havia forte apelo para o consumo de cereais secundários ou outros tipos de trigos, como a cevada, a aveia, o centeio e o milho, com os quais se produzia o pão da escassez, também conhecido como pão preto, consumido pelos pobres.

No século XIV, as crises periódicas e as tensões sociais tornaram-se mais agudas, aumentando a taxa de mortalidade em virtude da fome e da epidemia da peste negra e, como consequência, as cidades começaram a se esvaziar e cada região tentou produzir tudo que necessitava. Tais fenômenos aumentaram a insegurança alimentar; de acordo com Franco Junior (2001, s/p), bastava uma má colheita para que a mortalidade, rapidamente, se elevasse, pois eram grande as dificuldades de se obter alimentos em outras ou entre regiões. Tudo isto, naturalmente, teve reflexos no setor secundário (comércio). À medida que cada indivíduo gastava mais com alimentação, menos recursos tinha para consumir os bens manufaturados pelas oficinas de artesãos. Com a queda da taxa de crescimento populacional, diminuiu a procura de trigo e outros cereais produzidos no campo, e, consequentemente, os preços destes produtos baixaram. Contudo, os preços dos produtos artesanais manufaturados, produzidos nas cidades, continuaram subindo (tecidos de lã, de seda, artigos de madeira, osso, couro, metais e armas, dentre outros), reduzindo o poder de compra dos nobres (FRANCO JUNIOR, 2001, s/p).

Segundo Pedro (1995, p.128), com a diminuição do poder aquisitivo da nobreza, esta passou a exigir que os servos pagassem os impostos feudais em dinheiro em vez de produtos ou de trabalho. A pressão exercida pelos senhores feudais sobre os servos para aumentar suas rendas foi chamada de segunda servidão e levou estes últimos a total exaustão, provocando estagnação da produção. Diante da crise, surgiram ondas de rebeliões camponesas que se estenderam até as cidades. Nas cidades, ao mesmo tempo, a nobreza tentava limitar cada vez mais os rendimentos dos trabalhadores (artesãos), e, revoltados com as pressões, os camponeses e os trabalhadores urbanos se rebelaram contra a nobreza, explodindo grandes crises, conflitos que contribuíram para o enfraquecimento da nobreza e para o fim do feudalismo.

De acordo com Pedro (1995, p.143), com a crise da economia feudal, a vida urbana e o comércio se reorganizam, garantindo novo impulso e atraindo grandes contingentes da 
população rural para a cidade. Assim, as contradições internas do feudalismo, principalmente a luta de classe entre a nobreza e os servos, levaram este sistema à decadência. Dessa crise nasce uma nova Europa no século XV, com características econômicas, sociais e políticas muito diferentes do período feudal.

\section{AS PRÁTICAS DE CONSUMO NAS SOCIEDADES: DA IDADE MODERNA À CONTEMPORANEIDADE}

Este período caracteriza-se pelo minoramento da trilogia negra; - fomes, pestes e guerras - criando condições propícias às descobertas marítimas e às rotas comerciais, ao encontro de povos e de novos produtos. Como resultado, a partir do final século XV e início do século XVI, o comércio cresceu extraordinariamente, fruto, naturalmente, de modificações ocorridas no interior das sociedades feudais europeias (aumento da população, crescimento e desenvolvimento das cidades, desenvolvimento das manufaturas, dos transportes, das comunicações, dos mercados, das ciências, etc.).

As rotas comerciais permitiram o desenvolvimento das cidades ocidentais e a aproximação dos saberes das civilizações europeia, muçulmana e bizantina. De acordo com Arruda (1980, p. 13), a partir destas rotas foram aparecendo outras rotas secundárias, surgindo, em seus cruzamentos, feiras medievais, onde os comerciantes paravam para trocar e vender seus produtos. Pouco a pouco as feiras foram se prolongando e se estabilizando, tornando-se, inicialmente, centros permanentes de trocas e comércio e, depois, cidades chamadas burgos, e seus habitantes, burgueses.

Muitos artesãos estabeleceram-se nestas cidades ou centros urbanos e organizaram-se em corporações de ofício, de acordo com a mesma profissão. Conforme Arruda (1980, p. 13), as corporações defendiam os interesses dos artesãos, evitando a concorrência externa e a rivalidade entre os mesmos, dentro da mesma cidade, para isso, regulavam a qualidade dos produtos e o preço unitário da produção. Os horários de funcionamento das oficinas, o método de fabricação e a quantidade produzida eram também controlados, de forma a adequar a produção ao consumo (PEDRO, 1995, p. 142).

Para Volpi (2007, p.7), o surgimento da classe burguesa e a abertura de outras rotas comerciais entre a Europa e a Ásia acenderam as luzes para novo período na trajetória da humanidade e da nova sociedade de consumo, com especificidades diferentes daquela da Idade Antiga e da ldade Média (grifo da autora). Segundo Barbosa (2004, p.19), a partir do século de XVI registra-se o aparecimento de novos produtos, nos diversos segmentos sociais, fruto dessa expansão ocidental em direção ao oriente. 
No século XVII, a expansão marítima europeia proporcionou com as grandes navegações, a expansão das atividades comerciais e a acumulação de capitais para Europa. Ademais, propiciou igualmente o contato comercial entre várias partes do mundo (Europa, Ásia, África e América), favoreceu a ampliação dos conhecimentos geográficos, a relação entre culturas diferentes e grandes transformações na Europa e nas Américas. O comércio tornou-se mundial, deslocando o eixo econômico do Mediterrâneo para o Atlântico. É possível pressupor-se que a primeira etapa da globalização do final do século $X X$ aconteceu neste período do século XVII (ARRUDA, 1980, p.20).

Conforme Mota (1997, p.115), o afluxo de metais provenientes das colônias americanas causou uma verdadeira revolução no preço dos produtos. Os bens mais procurados eram o ouro e as especiarias. As especiarias (açúcar, café, condimentos, remédio e,ou, perfumaria) eram substâncias muito ativas, utilizadas em pequenas quantidades e caras, e empregadas para vários fins.

Em relação à necessidade de ampliar a produção de alimentos, produtos considerados especiaria, como o açúcar, que com o plantio da cana-de-açúcar nas colônias das Américas, e o café, vão se tornando alimentos de consumo em massa. Os condimentos, como a nozmoscada, o gengibre, a canela, o cravo e, sobretudo, a pimenta, diferentemente do açúcar e do café, continuaram raros e caros, isto se explica pelas técnicas limitadas de conservação existentes e pelos hábitos alimentares pouco desenvolvidos. Segundo Fausto (1996, p.13), havia, na realidade, à época, uma espécie de hierarquia no consumo destes condimentos, limitados à mesa dos ricos.

No século XVIII, a agricultura, que na sociedade de consumo da ldade Antiga e até o final da Idade Média era de subsistência, passa a ter fins comerciais. Produtos de muitas espécies alimentares, como o tomate, a batata, o milho, o arroz e outros, tornam-se importantes na alimentação ocidental e transformam-se em mercadoria, isto é, passam a ser vendidos, obtêm valor de troca. A produtividade agrícola aumentou consideravelmente, aumentou a oferta de alimentos, as pessoas passaram a viver mais tempo e, consequentemente, a população aumentou e a indústria ganhou mais mão de obra e consumidores.

\section{O CONSUMO NAS SOCIEDADES: DA REVOLUÇÃO INDUSTRIAL À SOCIEDADE DE CONSUMO CONTEMPORÂNEA}

O termo Sociedade de Consumo é um dos inúmeros rótulos, segundo Barbosa (2004, p. 7), utilizado por intelectuais, acadêmicos, jornalistas e profissionais de marketing e de outras áreas, para se referir à sociedade contemporânea. Entretanto, para esta autora, o termo 
sociedade de consumo traz alguns embaraços conceituais na medida em que o consumo, seja para satisfação de necessidades básicas e,ou, supérfluas, é uma prática que esteve sempre presente em toda e qualquer sociedade humana e não somente a partir da sociedade contemporânea. $\mathrm{O}$ indivíduo produzindo em sociedade é naturalmente o ponto de partida, desde as sociedades pré-capitalistas. Historicamente, o indivíduo apresenta-se em estado de dependência, que se inicia, de forma natural, na família, progredindo da família até as dimensões da tribo e destas até as diferentes formas de comunidade (MARX, 1983, p. 201).

De acordo com a teoria econômica, todas as comunidades primitivas tinham como objetivo básico o acúmulo de bens, principalmente de alimentos, para sua subsistência, ao passo que, para as sociedades pós-industriais, os objetivos vão além do consumo para sobrevivência ou subsistência. Para Veblen (1988, p.18), a eficiência industrial vai produzir bem mais do que o estritamente necessário para a subsistência, inclusive daqueles que se ocupam ou não do processo industrial.

Os estudos que tratam das transformações ocorridas com a Revolução Industrial concentram o foco desse fenômeno nas tecnologias de produção, com vista ao abastecimento do mercado em função do aumento populacional. Para Campbell (2001, p. 31), qualquer compreensão da Revolução Industrial deve pressupor, simultaneamente, a capacidade de abastecimento do mercado, bem como o desenvolvimento e ampliação do consumo e, consequentemente, a revolução do consumidor, que a qual promoveu modificações, tanto na procura quanto no abastecimento, conduzindo ao aumento da produção. Portanto, a justificativa para o crescimento da procura com base apenas no aumento exponencial da população e do poder aquisitivo não justifica totalmente a Revolução Industrial.

Segundo Campbell (2001, p. 33), os historiadores econômicos foram obrigados a aceitar que a resposta para a Revolução Industrial devia ser buscada também na mudança de valores e atitudes dos consumidores perante o consumo, no papel essencial desempenhado pela nova atitude moral do consumidor para com a aquisição de outros bens (produtos), além daqueles referentes às necessidades básicas. Para Veblen, com a nova base industrial, torna-se frequente a luta pela riqueza, como competição pelo aumento do conforto de vida, e, em 1899, em sua obra A teoria da Classe Ociosa estabeleceu o conceito de consumo conspícuo ao referir-se ao dispêndio efetuado com a finalidade precípua de mostrar riqueza, de exibir condição social, por meio da compra de artigos de luxo e de gastos ostentativos. Nesta mesma direção, Barbosa (2004, p. 15) acrescenta que, precedendo a Revolução Industrial, houve modificação dos hábitos de consumo e comerciais, ingrediente central da modernidade e da modernização ocidental direcionada para a nova sociedade do consumo. 
Para Arruda (1980, p. 119), a partir do século XVIII, a Revolução Industrial provocou transformações profundas e radicais na sociedade, consideradas revolucionárias não apenas nas técnicas, mas também em relação ao social. Além das transformações técnicas, comerciais e agrícolas, a Revolução Industrial pode ser considerada a passagem da sociedade rural para a sociedade industrial, a mudança do trabalho artesanal para o trabalho assalariado, a utilização da energia a vapor no sistema fabril, concomitante com a energia humana.

As consequências geradas pela Revolução Industrial tiverem efeitos em todas as áreas. A separação progressiva entre a agricultura e a produção artesanal, entre o campo e a cidade, levou a contraposição entre os bens de consumo produzidos no campo e os meios de produção na cidade. Gradualmente, esta separação entre os dois setores básicos da economia, agricultura e produção artesanal, vai sendo dissolvida, a produção capitalista de mercadoria destruiu definitivamente a unidade entre agricultura e produção artesanal e também dissolveu outros vínculos entre diversos setores das sociedades pré-capitalistas e, por conseguinte, penetrou, incessantemente, na produção simples de mercadorias (MANDEL, 1982, p.265).

Para tanto, segundo Huberman (1981, s/p), houve grande investimento no melhoramento das ferramentas e das máquinas para a indústria e a agricultura. A utilização de novos métodos, como a rotação de safras, as sementes selecionadas e o surgimento de novos equipamentos agrícolas, levou a um extraordinário aumento na produção de alimentos, como resultado da Revolução Agrícola.

À medida que aumentavam as populações e as cidades cresciam, eram construídas as ferrovias, seguidas depois pelas estradas, empurrando as lavouras para longe dos centros consumidores. Nesse processo, segundo Mandel (1982, p.265), os vegetais e outros alimentos frescos foram cedendo espaço, no comércio e na mesa das pessoas, aos produtos alimentares que podiam ser transportados com maior facilidade e que duravam mais tempo. Em função do aumento do consumo deste tipo de alimento, as indústrias de alimentos começaram a demandar matérias-primas agrícolas, propiciando a especialização crescente dos empreendimentos agronômicos.

\section{DO SURGIMENTO DAS INDÚSTRIAS DE ALIMENTOS À PREOCUPAÇÃO COM A SEGURANÇA ALIMENTAR E NUTRICIONAL}

Neste período, segundo Flandrini e Montarini (1998, p. 25), a Revolução Industrial incide, principalmente, no surgimento e na expansão das indústrias de alimentos, não só modificando os hábitos alimentares, mas, revolucionando a alimentação, mais propriamente, o consumo alimentar. Em termos históricos, começam a surgir soluções mais radicais para os problemas de 
abastecimento das populações europeias, concomitante com 0 rápido processo de industrialização da Inglaterra e de outros países da Europa ocidental (PEDROCCO, 1998, p. 763).

A indústria de alimentos passa a desenvolver técnicas de conservação dos alimentos, com o objetivo de aumentar a produtividade. Destaca-se o método descoberto pelo francês Nicolas Appert, que buscou produzir conservas, primeiramente em garrafas de champanhe e, mais tarde, em latas de ferro. Appert fez experiências com a máquina a vapor, conseguindo, assim, que o cozimento ultrapassasse a temperatura de ebulição da água (ALIMENT..., 2013, s/p).

Em 1802, Appert abriu uma fábrica de conservas para suprir a armada francesa e, em 1812, foi fundada a primeira fábrica de conservas de alimentos para o mercado consumidor, acontecimento que transformou, à época, a forma de acondicionar alimentos na Europa. Outro processo criado, no mesmo período, foi a pasteurização, quando o cientista francês Louis Pasteur resolveu o problema da rápida fermentação de vinhos que prejudicava a indústria vinícola da França. O mesmo método foi aplicado, com sucesso, na produção da cerveja, no século XX e na pasteurização para o tratamento do leite e de outros produtos (Op.cit. 2013, s/p.).

Concomitante à revolução da alimentação, mais propriamente do consumo alimentar, em termos históricos, segundo Pedrocco (1998, p. 763), a expansão demográfica progressiva subverte o equilíbrio, já precário, dos recursos alimentares nas regiões em vias de industrialização. As condições de vida das classes trabalhadoras, que vivem nas cidades, tornam-se, então, particularmente penosas, porque os alimentos são insuficientes e muito caros, sobretudo por causa da carência do sistema de abastecimento, prejudicado pela falta de condições dos matadouros e dos mercados para acolher o excedente de gado e de mercadorias, que é o corolário do aumento de consumo.

Nos primeiros tempos da Revolução Industrial, uma longa série de boas colheitas propiciou o aumento da população e seu sustento e, de certa forma, melhoria das condições de vida. Entretanto, com o avanço da industrialização, a saúde da população urbana começou a se deteriorar, principalmente pela imensa concentração populacional nas cidades, sofrendo a população com as epidemias, as péssimas condições de habitação, a estafa causada pelo trabalho e, sobretudo, pela alimentação insuficiente e inadequada.

Esta conjuntura faz surgir, neste período, a preocupação com a Segurança Alimentar, como questão de segurança nacional para todos os países. A discussão apontava para a exigência, por parte de cada país, de formação de estoques estratégicos de alimentos e fortalecimento da visão sobre a necessidade de buscar a autossuficiência do consumo de 
alimentos. A Segurança Alimentar passou a ser temática debatida com grande importância em todos os países do mundo.

Logo após a Segunda Guerra Mundial (1939-1945), e, em particular, a partir da constituição da Organização das Nações Unidas (ONU), em 1945, o conceito de segurança alimentar ganha força a custa de interesses divergentes. Segundo Macedo (2009, p.33), dois pontos de vista antagônicos se evidenciam, gerando conflitos e tensão política. Para os recémcriados organismos internacionais, a exemplo da FAO (Organização das Nações Unidas para Alimentação e Agricultura), a segurança alimentar é entendida como o direito humano ao acesso ao alimento de qualidade. Em contraposição, as Instituições de Bretton Woods, tais como o Fundo Monetário Internacional (FMI) e o Banco Mundial, entendem a segurança alimentar como mecanismo de mercado, a ser garantido pelo próprio mercado e não como direito que deve ser garantido pelo Estado.

O problema da insegurança alimentar no mundo era visto pelo mercado como decorrente da produção insuficiente de alimentos, principalmente nos países pobres. A percepção era que as crises na oferta e na distribuição de alimentos seriam causadas pelas altas taxas de natalidade das populações pobres e pelas condições climáticas adversas (MIRANDA NETO, 1985, p.12). Entretanto, rigorosa análise desse problema realizada pelo Chicago Council on Foreign Relations, à época, desmentiu categoricamente essas hipóteses ao constatar que a produção agrícola crescera em cerca de $50 \%$ nos países pobres; que houvera aumento de 0,5\% ao ano na produção per capita de alimentos; que a taxa de crescimento da população mundial, assim como a pressão sobre a oferta de alimentos, estava declinando; que grandes impactos adversos do clima sobre a produção de alimentos não estavam previstos até o ano 2000 (JOHNSON, 1980 apud MIRANDA NETO, 1985). Neste cenário, após longo processo de lutas e conflitos, a pactuação dos direitos humanos ocorre com a Declaração Universal dos Direitos do Homem, em 1948. A Declaração Universal é resultante da luta dos povos contra a opressão e abusos de poder, no momento em que a humanidade ainda se encontrava sob o forte impacto das atrocidades ocorridas durante a segunda guerra (BRASIL, 2013, p. 45).

Durante a Assembleia Geral da ONU, em 1966, foi assinado o Pacto Internacional dos Direitos Econômicos, Sociais e Culturais (PIDESC), no qual foi reconhecido o direito de todos a um padrão de vida adequado, definindo-se duas dimensões indivisíveis do Direito Humano à Alimentação Adequada (DHAA): $\ominus$ o direito de estar livre da fome e da má nutrição e o direito à alimentação adequada.

Na década de 70, particularmente entre 1972 e 1974, devido a problemas climáticos ocorreram duas grandes quebras da produção de alimentos nas principais áreas produtoras de 
alimentos, contribuindo, drasticamente, para a diminuição dos estoques mundial de cereais (FAO, 2000, s/p.). Essa queda de estoque contribuiu para tornar a subnutrição problema mundial, que afetou milhares de pessoas (MENEZES, 1998, s/p). No mesmo período, duas fortes secas atingiram a África. A primeira ocasionou a morte por fome de cerca de 100 mil pessoas nos países da África Subsaariana. A segunda seca atingiu a Etiópia e matou, também por fome, cerca de 200 mil pessoas. Paralelamente, o mundo viveu a crise do petróleo, que provocou abrupta subida dos preços dos combustíveis, fertilizantes e pesticidas, agravando a crise alimentar (TAKAGI, 2006, p.12).

Esse cenário propiciou a realização da 1a Conferência Mundial de Alimentação, em 1974, organizada pela FAO. Ainda que os estudos ressaltassem que o fator crucial da multicausalidade dos problemas de alimentação e nutrição era, sobretudo, a desigual distribuição e o acesso inadequado aos alimentos por parte dos pobres, sendo a pobreza estabelecida como a principal causa da desnutrição, na ocasião da referida conferência, a discussão centrou o enfoque, sobremodo, nas políticas agrícolas, reforçando a crença de que a segurança alimentar dependia, fundamentalmente, de política de armazenamento estratégico, devendo-se fazer crescer os estoques e assegurar a consolidação de acordos internacionais sobre diferentes produtos agrícolas. Com o enfoque totalmente voltado para o produto e a produção, a dimensão do Direito Humano à Alimentação Adequada foi colocada em segundo plano (INSTITUTO CIDADANIA, 2001, p.11).

Foi a partir desse contexto que a Revolução Verde se intensificou, devido, principalmente, pelo uso de sementes de alto rendimento, pesticidas, fertilizantes, irrigação e mecanização, inclusive no Brasil, originando enorme impulso na produção de soja (BRASIL, 2013, p.11). Essa estratégia, segundo Maluf, Menezes e Valente (1996, p. 74), aumentou a produção de alimentos, mas, paradoxalmente, provocou a deterioração da qualidade dos mesmos e o aumento do número de famintos e de excluídos, em função da falta de garantia de acesso físico e econômico aos alimentos, em decorrência da pobreza e da falta de acesso aos recursos necessários, principalmente, a renda e a terra.

Na década de 90, o conceito de Segurança Alimentar foi ampliado, incorporando novas noções de acesso ao alimento e de qualidade, como mostra Belik (2003):

toda população deve ter pleno acesso físico e econômico a alimentos seguros e nutritivos que satisfaçam as suas necessidades e preferências nutricionais para levar uma vida ativa e saudável (BELIK, 2003, p.23).

Somando-se a isso, nas declarações da Conferência Internacional de Nutrição, realizada pela FAO e pela Organização Mundial da Saúde em Roma, em 1992, o conceito de Segurança 
Alimentar agrega, definitivamente, o aspecto nutricional e sanitário dos alimentos, passando a ser designado de Segurança Alimentar e Nutricional. Além disso, o conceito incorporou, também, as noções de acesso a alimentos seguros (não contaminados biológica ou quimicamente) e de qualidade (nutricional, biológica, sanitária e tecnológica), produzidos de forma sustentável, equilibrada e culturalmente aceitável (VALENTE, 2002, p.54).

Contudo, mais de dez anos após a I Conferência Internacional de Nutrição, a FAO constatou que os objetivos de erradicar a fome no mundo estavam longe de ser alcançados, pois estimativas indicavam que haveria cerca de 680 milhões de pessoas famintas no mundo no ano 2010. Na perspectiva de discutir essa questão, em novembro de 1996, a FAO realizou a Cúpula Mundial da Alimentação em Roma, reunindo representantes de 185 países e da Comunidade Europeia, com o objetivo de renovar o compromisso global de eliminar a fome e a subnutrição e atingir a segurança alimentar para todas as pessoas. Nessa ocasião, os países participantes, inclusive o Brasil, assinaram a Declaração de Roma, firmando o compromisso de erradicar a fome em todos os países, com a meta inicial de reduzir, pela metade, o número de subnutridos em seu território, até o ano de 2015 (BELIK, 2003, p. 9; TAKAGI, 2006, p. 15).

\section{CONSIDERAÇÕES FINAIS}

O modo de produção de alimentos se modificou historicamente e, a cada época, está intimamente ligado ao processo de desenvolvimento econômico, social, político e cultural, bem como a produção e reprodução da vida material da sociedade. O ser humano passou a dominar o processo de produção de alimentos, proporcionou avanços que permitiu a humanidade lutar contra a fome e superá-la. Contudo, com o surgimento da propriedade privada, na sociedade moderna, parte da produção de alimentos passa a ser produzida a partir da perspectiva mercantil, voltada para o lucro, sem a preocupação de produzir alimentação adequada, saudável e acessível a todos. A preocupação com lucro inviabiliza, na sociedade contemporânea, a abolição total e definitiva da fome. Somando-se a isso, as mudanças ocorridas nos processos de organização das sociedades (industrialização e globalização), eminentemente urbanas, resultaram no aumento expressivo da obesidade e do excesso de peso nas populações.

Apesar dos avanços observados na conformação da sociedade de consumo contemporânea, pode-se observar a existência de problemas expressivos, relacionados com a segurança alimentar e nutricional, que não permitem afirmar que o direito humano à alimentação adequada é efetivado. Aparentemente, o problema é de escassez da oferta de alimentos, contudo, os estudos mostram que se trata da expressão da injusta distribuição global, fato que 
tem afetado, sobretudo, os mais pobres. Considerando este contexto, o estudo procura mostrar as ambiguidades e contradições em volta da provisão da segurança alimentar e nutricional. É possível afirmar que, apesar das conquistas e dos avanços no campo dos conceitos e no conjunto de normas da legislação pertinente à Segurança Alimentar e Nutricional na sociedade de consumo contemporânea, este estudo, corroborando outros, identifica existirem aspectos/fatores que limitam a efetivação do Direito Humano à Alimentação Adequada.

\section{REFERÊNCIAS}

ALIMENTAÇÃO fora do lar. Quais são as fases da história da alimentação. Acesso em: 25/07/2013. [Visualizar]

ARRUDA, José Jobson de Andrade. História moderna e contemporânea. 12 ed. -São Paulo: Ática, 1980. Google

BARBOSA, Lívia. Sociedade de consumo. Rio de Janeiro: Jorge Zahar, 2004. 68 p. Google

BATISTA, João Marcos. A evolução da economia: uma abordagem histórica sobre os principais modelos, teorias e pensadores. RENEFARA - Revista Eletrônica de Educação da Faculdade Araguaia - ISSN: 2236-8779. v. 2, n. 2, 2012. Acesso em 02/07/2015. [Visualizar] Google

BRASIL. O direito humano à alimentação adequada e o sistema nacional de segurança alimentar e nutricional / organizadora, Marília Leão. - Brasília: ABRANDH, 2013. 263 p. Google

BELIK, Walter. Segurança alimentar: a contribuição das universidades / Walter Belik; [Carmen Weingrill, (coordenadora); Benjamin S. Gonçalves, Leno F. Silva, Paulo Itacarambi (colaboradores)] — São Paulo: Instituto Ethos, 2003. Google

CAMPBELL, Colin. Como se explica a revolução do consumidor na Inglaterra do século XVIII. In: CAMPBELL, Colin. A ética romântica e o espírito do consumismo moderno. Rio de Janeiro: Rocco, 2001. Google

CEDAC. O trabalho - A mercadoria. Coleção "Brasil dos trabalhadores". 2. ed. - São Paulo: Edições Loyola, 1982. Google

DEININGER, Jürgen. A teoria econômica dos Estados antigos: a questão do capitalismo na Antiguidade na visão de Weber. Tempo soc. v. 24, n.1, São Paulo, 2012. Google crossref

DIAMOND, Jared. The Worst Mistake in the History of the Human Race. Discover Magazine, May 1987, p. 64-66. Google

FAUSTO, Boris. História do Brasil. São Paulo: Edusp, 1999

FLANDRIN, Jean-Louis e MONTARINI, Massimo. História da Alimentação. Tradução MACHADO, L. \& TEIXEIRA, G. São Paulo: Estação Liberdade, 1998. Google 
FRANCO JÚNIOR, Hilário. A Idade Média: o nascimento do ocidente / Hilário Franco Júnior. 2. ed. rev. e ampl. -- São Paulo: Brasiliense, 2001. Google

INSTITUTO CIDADANIA. Projeto Fome Zero: Uma proposta de política de segurança alimentar para o Brasil. Outubro de 2001. São Paulo. Google

LIMA, Renato. Consumo e Sociedade. Recife: Prazer e Ler, 2007.

MACEDO, Dione Chaves de; TEIXEIRA, Estelamar Maria Borges; JERÔNIMO, Marlene; BARBOSA, Ozeni Amorim; OLIVEIRA, Maria Rita Marques de. A construção da política de segurança alimentar e Nutricional no Brasil. Rev. Simbio-Logias, v.2, n.1, mai, 2009. Google

MANDEL, Ernest. A expansão do Setor de Serviços, a "Sociedade de Consumo" e a Realização da Mais-Valia. In: Capitalismo Tardio. São Paulo: Abril Cultural, 1982. Google

MARX, Karl; ENGELS, Friedrich. A Ideologia alemã: teses sobre Feuerbach. São Paulo: Moraes, 1984. Google

MENEZES, Francisco. Panorama Atual da Segurança Alimentar no Brasil. Documento elaborado para Actionaid para a discussão no Encontro Nacional de Segurança Alimentar e Nutricional. São Paulo, 1998. 15/06/2014. [Visualizar]

MIRANDA NETO, Manoel Jose de. Os lucros da fome: O mito da escassez de alimentos. 2 ed. - Rio de Janeiro: Dois Pontos, $1985 . \quad$ Google

MOTA, Myriam Beecho. História: das cavernas ao Terceiro Milênio: volume único. 1 ed - São Paulo: Moderna. 1997. Google

NAVARRO, Roberto. Como o homem caçava e se alimentava na pré-história? Edição 15. 01.07.2015. [Visualizar]

PEDRO, Antonio. História Geral: compacto, 2ํgrau. - Ed. Atual, ampl. e renovada - São Paulo: FTD, 1995. Google

PEDROCCO, G. A Indústria Alimentar e as novas Técnicas de conservação. IN: FLANDRIN, Jean-Louis e MONTARINI, Massimo. História da Alimentação. Tradução MACHADO, L. \& TEIXEIRA, G. São Paulo: Estação Liberdade, 1998. Google

PITTA, Valter. O comércio no império romano. 2010. Acesso em: 02/07/2015. [Visualizar]

RECINE, Elisabetta; RADAELLI, Patrícia. Alimentação e cultura. Brasília: Ministério da Saúde; 2008. Acesso em: 12/05/2015. [Visualizar]

SANTOS, Andréia Mendes dos. Sociedade do consumo: criança e propaganda, uma relação que dá peso. Tese (Doutorado em Serviço Social). Faculdade de Serviço Social, Pontifícia Universidade Católica do Rio Grande do Sul. Porto Alegre, 2007. Google

SHAN, Viviane Li Xiao. Naturação em Jardins Terapêuticos no Contexto Socioambiental de Unidades Hospitalares. Rio de Janeiro: UFRJ / ESCOLA POLITÉCNICA, 2015. Google 
SOUZA, Nali de Jesus de. Uma introdução à história do pensamento econômico. Relatório Pesquisa da área de História Econômica, realizada no NEP PUCRS. Google

TAKAGI, Maya. A Implantação da Política de Segurança Alimentar e Nutricional no Brasil: seus limites e desafios. Tese (Doutorado em Economia aplicada) - Programa de PósGraduação em Economia Aplicada do Instituto de Economia da Universidade Estadual de Campinas, SP. 2006. Google

VALENTE, Flavio Luiz Schieck. Fome e desnutrição: determinantes sociais. São Paulo: Cortez, 1986. 107p. Google

VALENTE, Flávio Luiz Schieck. Do combate à fome à Segurança Alimentar e Nutricional: o direito humano à alimentação adequada. In: VALENTE, Flávio Luiz Schieck. Direito humano à alimentação adequada: desafios e conquistas. São Paulo: Cortez Editora, 2002, p.40-43. Google

VEBLEN, Thorstein. A teoria da classe ociosa: um estudo econômico das instituições. Tradução de Olívia Krähenbühl. - 3 ed. - São Paulo: Nova Cultural, 1988. Google

VIANA, Nildo. Contradições do modo capitalista de produção de Alimentos. 02/08/2014. [Visualizar] Google

VOLPI, Alexandre. A história do consumo no Brasil: do mercantilismo à era do foco no cliente. Rio de Janeiro: Elsevier, 2007. Google 